\title{
Impact of traffic zones on mobility behavior in Tehran, Iran
}

\author{
Fatemeh Salarvandian \\ University of Tehran \\ fsalarvandian@ut.ac.ir
}

Marco Helbich

UtrechtUniversity

m.helbich@uu.nl

\author{
Martin Dijst \\ Utrecht University \\ M.J.Dijst@uu.nl
}

\begin{abstract}
The use of private cars has increased rapidly in developing countries, causing congestion and pollution in cities. In Iran, measures have been taken to manage the extensive automobile use in Tehran. Two downtown traffic zones were introduced: The Restricted Traffic Zone (RTZ) based on pass permission and the Odd-Even Zone (OEZ) based on license-plate number. This article investigates how and to what extent traffic zoning influences mobility behavior in Tehran. Two neighborhoods within these zones and one elsewhere were selected to compare the impact of traffic zoning on mode choice and travel time by means of regression analyses. The results show that zoning has decreased driving in both neighborhoods; although compared to the RTZ, the OEZ has had a limited impact. While car use has diminished in both neighborhoods compared to the area without restrictions, travel time has increased in the traffic zones. An explanation might be the low quality of the infrastructure for alternative modes (e.g., cycling). Tehran's spatial functional specialization and the monocentric urban structure induce more car trips and longer travel times, regardless of traffic restrictions. Policymakers are advised to integrate restrictions on automobile use with improvements in public transport to enhance the impact of traffic zones.
\end{abstract}

Keywords: Travel demand management, Restricted Traffic Zone, Odd-Even Zone, mode choice, travel time.

\section{Article history:}

Received: November 1, 2016

Received in revised form: May

3, 2017

Accepted: August 15, 2017

Available online: November 29,

2017

\section{Introduction}

The rapid growth of car use in large cities has raised concerns about congestion and pollution. The key to counteracting such developments is to impose measures such as travel demand management (TDM) that aim to influence peoples' car use (VTPI, 2004). Similar to metropolitan areas in the developing world, Tehran (Iran) suffers from rising car usage and traffic volume, as well as their negative environ-

Copyright 2017 Fatemeh Salarvandian, Martin Dijst \& Marco Helbich

http://dx.doi.org/10.5198/jtlu.2017.1087

ISSN: 1938-7849 | Licensed under the Creative Commons Attribution - Noncommercial License 3.0

The Journal of Transport and Land Use is the official journal of the World Society for Transport and Land Use (WSTLUR) and is published and sponsored by the University of Minnesota Center for Transportation Studies. 
mental consequences. With a population of approximately 8.3 million, Tehran's transport policies need to deal with four million vehicles and 17.4 million trips each day (Atlas Tehran, 2010; Tehran Comprehensive Transportation and Traffic Studies, 2013). Furthermore, the share of car-based trips increased from 39 percent in 2011 to 45 percent in 2013. Inner-urban congestion has turned Tehran into one of the world's most polluted cities (WHO, 2014), and close to 50 percent of Tehran's mobility-related pollution may be attributed to light duty vehicles e.g. private cars (Allen, 2013).

Therefore, the city administration has made attempts to encourage public transport (Tehran Comprehensive Transportation and Traffic Studies, 2013). In addition, two downtown traffic zones have been introduced to restrict car use. In one, the Restricted Traffic Zone (RTZ), motorized access to the city center is limited on weekdays between 6:30 a.m. and 5:00 p.m. Except for public transport, taxis and motorcycles, only vehicles with a daily, weekly or annual permission pass are allowed to enter this zone during that time frame. Entering the RTZ is monitored electronically by cameras. The other, the Odd-Even Zone (OEZ), resembles measures taken in Beijing (Viard \& Fu, 2013). Encircling the RTZ, car usage is limited to odd or even license-plate numbers on weekdays between 6:30 a.m. and 7:00 p.m. OEZ gateways are controlled by the police without electronic means. The rest of Tehran has no restrictions on car use.

However, little is known about the impact of these traffic zones on peoples' mobility behavior, though such knowledge is crucial for several reasons. First, the traffic zoning in Tehran is more complex than that analyzed in other studies, notably of London, Singapore and Beijing (Strompen, Litman, \& Bongardt, 2012). Having two zones instead of one, Tehran's situation allows cross-comparisons within the same environment and permits an analysis of differences between and impacts of these measures. Second, Tehran is characterized by a low level of economic growth (The World Bank, 2014) and low fuel prices (International Energy Agency, 2010), but also by specific sociocultural features such as aggressive and risky driving habits (Shams \& Rahimi-Movaghar, 2008), a limited presence of women in public space, and gender segregation (Amir-Ebrahimi, 2006). For these reasons, this research complements existing studies conducted in Western and Asian countries.

The aim of this research is to understand how and to what extent traffic zoning influences mobility behavior in Tehran. Concretely, we analyze the effects that restricted car usage in two traffic zones have on mode choice and travel time. For that purpose, a unique travel diary-based dataset was assembled in February 2014. Using the findings of this study, not only the transportation authorities in Tehran but also decision-makers in Asian metropolises may be able to evaluate the outcomes of the traffic zone implementation and profit from Tehran's experiences in implementing zone-based traffic policies. The paper is structured as follows. Section 2 reviews the literature while section 3 outlines the research design. Key results are presented in section 4 and section 5 outlines the major conclusions.

\section{$2 \quad$ Literature review}

This section summarizes the literature on traffic measures, especially studies on how car restriction policies change private car usage and daily travel times. The literature on different responses to TDMs is reviewed in different contexts (e.g., economic, social and political circumstances). As Goodwin (2004) states, when traveling conditions change, people might change their driving styles, alter their routes, the time they travel, the frequency of trips, the method of transport, the sequence of activities on a round trip, etc. Many authors have argued that behavioral changes are affected by socio-demographic characteristics (e.g., age, gender) (Arentze, Hofman, \& Timmermans, 2004), trip attributes (e.g., purpose, destination, mode), and the type of traffic measures and cost of toll (Loukopoulos, 2005).

According to Strompen et al. (2012), the impacts and benefits of TDM strategies can vary significantly depending on where and how they are implemented. Caution is recommended when applying 
TDMs in developing countries due to special circumstances such as high rates of car ownership (Dargay, Gately, \& Sommer, 2007), income inequalities (Strompen et al., 2012), inefficient and insufficient public transport, walking and cycling facilities (Dissanayake \& Morikawa, 2002). Besides, these countries do not have the financial resources, the intelligent transportation systems or the infrastructures necessary for implementing TDMs. Moreover, Litman believes that travel demand is more diverse in developing countries and varies greatly depending on their geographic, demographic and economic conditions (VTPI, 2004). Broaddus, Litman, and Menon (2009), state that developing countries are inclined to apply measures that have a direct impact upon drivers. Hence, hard measures such as vehicle use restriction and fees tend to be utilized more in these countries.

Cities in developing countries, notably Mexico City, Bogotá and Beijing, use the scheme of licenseplate restriction, while cities in developed countries (e.g., London, Stockholm) tend to implement more complicated schemes such as congestion pricing (Broaddus et al., 2009). Tehran stands out in this regard because RTZ and OEZ schemes have been put in place together. Entering the RTZ in Tehran requires buying a pass, as one would do in many cities in developed countries with congestion pricing. The costs for a daily pass range from 5 to 11 USD depending on the type of the pass and the entering time. In these cities, everybody can buy a pass to enter the car-restricted zone. But unlike most of these cities, permission in Tehran is only available to a select group (e.g., physicians, disabled motorists, governmental organizations). It seems that Tehran's RTZ combines a physical measure to limit car use with a financial one (pricing).

Most studies discuss change in mode choice as a reaction to TDM measures that fall under shortterm adaptations (e.g., Loukopoulos, 2005). Liguang, Haozhi, Yulin, and Zhaorong (2010) show when a car restriction measure based on odd- and even-numbered license plates was implemented in Beijing during the Olympic Games, 50 percent of the car owners shifted to public transport. Similar findings are reported by Litman (2011), who stated that after implementing congestion pricing in London, which is a kind of RTZ policy, over 85 percent of the morning peak-period trips towards the city center were by public transport. However, other findings demonstrate that traffic policies do not necessarily lead to a switch to public transport. For example, Mahendra (2008) mentions an alternative: buying additional cars with different license plates as a response to restrictions in Mexico City. The same happened in Beijing, where Wang, Xu, Zheng, and Qin (2013) note that people have invented "surprising" ways such as covering the plates, or borrowing other people's plates or cars on the days their own cars were banned. In Tehran, people do not seem to be purchasing a second vehicle with a different license-plate number due to low economic growth and welfare level compared to, for instance, Beijing or Mexico City (The World Bank, 2014). Tehran's OEZ is controlled by cameras, as in Beijing (Viard \& Fu, 2013). However, there is still wide scope for violation because the fine for violating the odd-even-rule is not that high (about 5 USD).

There is some evidence of the impact of car restriction on travel duration. For instance, an increase in average speed reflects a decrease in congestion, which in turn reduces travel time and decreases queuing time at junctions (Leape, 2006). Litman (2011) reports for London that average traffic speed on restricted days increased by 37 percent from eight miles per hour prior to the charge up to 11 miles per hour. Furthermore, delays during peak time dropped by 30 percent for private vehicles and 50 percent for buses. Similar results are reported for Stockholm, Sweden. Albalate and Bel (2008) state that after the introduction of car restrictions, the average journey times declined in Stockholm's inner city. The queuing times dropped by approximately a third in the morning rush and were halved in the afternoon rush. Similar findings have been reported for Beijing by Liguang et al., (2010). Compared to the nonrestricted period, travel speed increased by approximately 16 percent in the morning peak time and 14 percent in the evening peak time. In Singapore, the provision of high-quality walking, cycling, and pub- 
lic transit facilities alongside congestion pricing has made vehicle restriction successful (Strompen et al., 2012). Padayhag and Bahoy (2013) reveal that during Number Coding Scheme day in Metro Manila in the Philippines, commuters tend to go to work early and arrive at home late to avoid the time frame during which the vehicles are banned. They found that the use of public transport is less likely to be chosen as an alternative mode to travel for work due to the poor service (i.e., security, safety, punctuality and reliability) and comfort (Susilo, Joewono, \& Santosa, 2010).

Unlike the benefits reported in many other cities, the improvement of cycling and walking in Tehran may not be an effective solution due to geographical conditions (e.g., pronounced topography) and sociocultural attitudes (e.g., cycling by women is frowned upon, though not legally banned). Therefore, improvement of public transport might be more effective as it would encourage people not to use their private car. Furthermore, as highlighted in the Tehran Master Plan (2006), Tehran needs to be envisioned as a polycentric transit-oriented city, with several centers of urban activities, rather than as a monocentric private-car-oriented configuration (Allen, 2013). In light of this literature review, we conclude that the effectiveness as well as the consequences of TDMs might differ from one country to another. Apparently, people choose among a wide range of alternatives in response to traffic policies depending on where, how and when these policies are implemented. Therefore, policymakers should adjust their policies to the circumstances of their cities.

\section{Research design}

\subsection{Study area}

The study area was delimited to those parts of Tehran that have imposed some restrictions on driving. The initial demand management schemes for Tehran were launched in September 1979 to prohibit cars from entering the downtown at specified times on certain streets. Since then, the area subject to restriction has been extended while the window of time for driving has been limited. Since 1991, Tehran has been partitioned into three traffic zones. In the first one, car access to the city center is prohibited from 6:30 a.m. to 5:00 p.m. on weekdays and from 6:30 a.m. to 1:30 p.m. on Thursdays; exceptions are made for Fridays and days off. This Restricted Traffic Zone (RTZ) covers nearly $32 \mathrm{~km} 2$ of the full $730 \mathrm{~km} 2$ of Tehran. The RTZ is surrounded by a second zone, where private cars are allowed to drive on the basis of an odd- vs. even-numbered license plate. Cars with plates ending on the right with odd numbers are authorized for use on odd-numbered days of the week and those with plates ending in even numbers for use on even-numbered days. This Odd-Even Zone (OEZ) covers $74 \mathrm{~km}^{2}$. In the OEZ, people are allowed to drive from 6:30 a.m. to 7:00 p.m.; exceptions are made for Fridays and days off (i.e., holidays and weekends). Car owners are penalized if they drive in these prohibited times and areas. Drivers pay between five and 230 USD, depending on the type of pass they obtain (i.e., daily, weekly or annual), but not everyone is eligible. Around 80,000 car owners pay an annual fee to enter the RTZ of Tehran and about 40 percent of them work for the government (Shoar, 2008) Even with a pass, however, on days of heavy pollution, only public transport, taxis and motorcycles are allowed to enter the RTZ. The third zone encompasses the rest of the city, where no vehicles are prohibited.

For sampling purposes, the Tehran municipal division was used. It divides the city into 22 districts, each of which includes several neighborhoods. The study area was limited to three neighborhoods (i.e., in district 11, 6 and 1), each located in one of the traffic zones. The neighborhood selection grounded on the following considerations. The area, population density, built-up environmental attributes (e.g., size of commercial and residential areas) and the socio-demographic and-economic profile should be comparable as much as possible. However, due to the limited number of neighborhood options, it was not possible to select neighborhoods which were on all criteria exactly comparable. District 11 is one of the oldest in Tehran; it encompasses important political, economic and scientific centers; and it lies 
entirely within the RTZ. According to studies by the Tehran municipality (Tehran Atlas, 2010; Tehran Comprehensive Transportation and Traffic Studies, 2013), 60.1 percent of the roads in this district have an inappropriate volume capacity ratio. Besides, the average speed of vehicles is limited to 14.1 kilometers per hour. One of the neighborhoods in this district, namely Sheikhadi, was selected for study. The second neighborhood selected, Qezelqale, lies in the OEZ in district 6. Due to its centrality, this area is a crucial part of the urban core; it serves key transportation, administrative and political functions. Similarly, the volume capacity ratio in 53.2 percent of streets in this area is inappropriate and the average speed of vehicles is 15 kilometers per hour. Some parts of district 6 are in the RTZ while others lie in the OEZ. The third neighborhood, Qeitarie, was selected from district 1; it lies outside both traffic zones. Just 23.6 percent of roads in district 1 have a volume capacity ratio at an inappropriate level while the average vehicle speed increased to 28 kilometers per hour. Due to its natural features, Qeitarie is one of the city's most desirable places to live. A comparison with official district data from the Atlas of Tehran (2010) confirmed that the sample represents the population well (e.g., district 6 has a car ownership rate of 61 percent while in our sample the rate is 62 percent). Detailed socioeconomic and demographic data at the neighborhood level is not accessible in Tehran. Table 1 gives some basic characteristics of the neighborhoods, while Figure 1 shows the extent of the traffic zones.

Table 1: Basic characteristics of the three neighborhoods

\begin{tabular}{|l|c|c|c|}
\hline & $\begin{array}{c}\text { Restricted Traffic } \\
\text { Zone (Sheikhadi) }\end{array}$ & $\begin{array}{c}\text { Odd-Even Zone } \\
\text { (Qezelqale) }\end{array}$ & $\begin{array}{c}\text { Outside the two traffic } \\
\text { zones (Qeitarie) }\end{array}$ \\
\hline Average household size (number of persons) & 3.3 & 3.0 & 2.9 \\
\hline Population density $\left(\mathrm{km}^{2}\right)$ & 20,699 & 20,943 & 20,575 \\
\hline Total population & 17,530 & 18,767 & 22,609 \\
\hline Area $\left(\mathrm{km}^{2}\right)$ & 0.84 & 0.89 & 2.1 \\
\hline Number of metro stations near residents' home & 3 & - & 6 \\
\hline Number of bus stops near residents' home & 12 & 12 & - \\
\hline $\begin{array}{l}\text { Number of Bus Rapid Transit stops in neigh- } \\
\text { borhood }\end{array}$ & 4 & - & 2 \\
\hline
\end{tabular}

Source: ICT Organization of Tehran Municipality (2014)

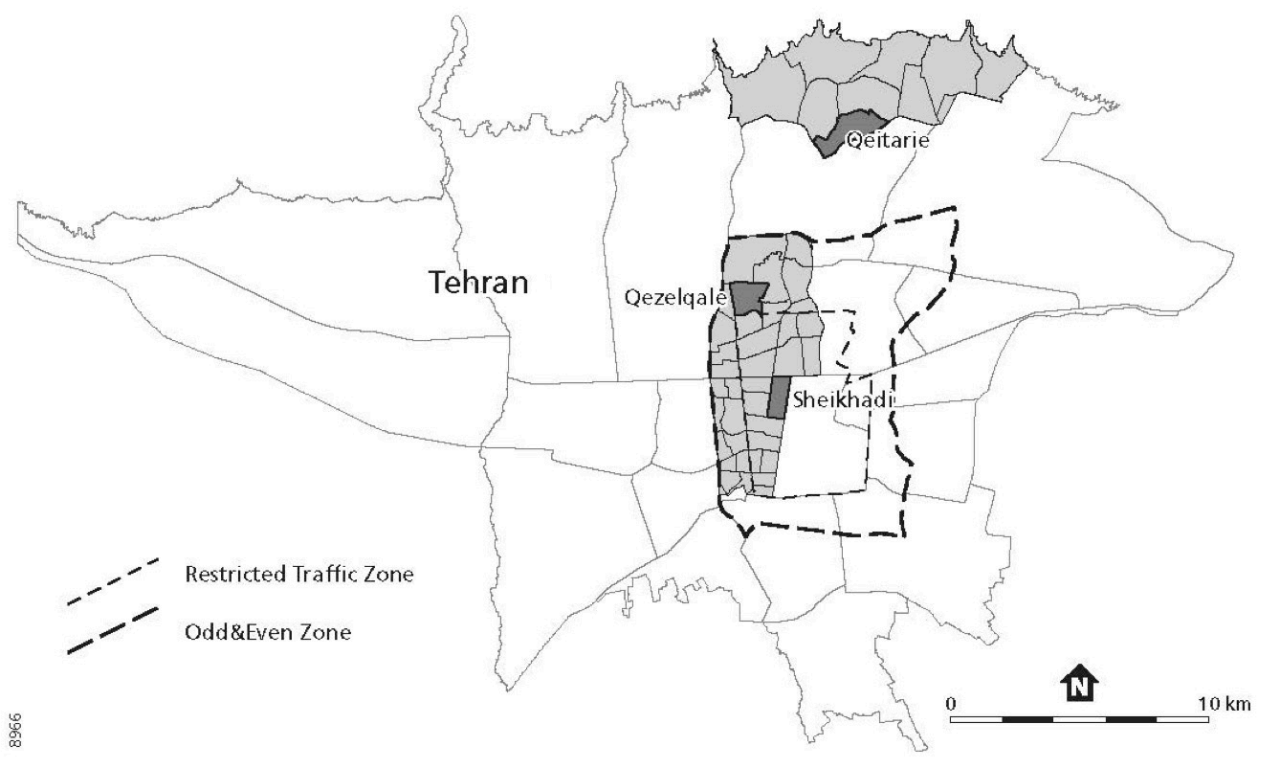

Figure 1: Neighborhoods' situation with respect to traffic zones 


\section{$4 \quad$ Data}

The data used in this study stem from a travel diary and a questionnaire carried out in February 2014. The dataset comprises 150 persons who were systematically sampled within each neighborhood (in total 450 people). After determining a starting point in each neighborhood, each fifth address was selected. Each member of a household with an age over 18 years was asked to fill in the survey. Respondents were able to choose between an online or paper-based version of the survey. 24.3 percent of respondents completed the online survey and returned it via email. The paper-based questionnaires were gathered a week later by the authors. The overall response rates were 92.6 percent, 94 percent, and 98 percent in the neighborhood locating in RTZ, OEZ, and out of the two zones. Although the sample size is limited, it is not unusually small and similar sizes are used in other transport studies (e.g., Van Eck, Burghouwt, \& Dijst, 2005). Respondents were asked to answer questions about their personal and household characteristics (e.g., gender, age, income, education, family type, presence of a child under 12 years). Moreover, they were asked to keep a travel diary giving trip-specific information for two days, including the travel day, trip start and end times, purpose and mode. To ensure that the trips were conducted during the limited access times, we considered the day of the trip as well as the start time and end time of each trip. Two characteristics of travel behavior, namely mode choice and travel time, were taken as the dependent variables. We distinguished five main modes of transport: walking, public transport (i.e., bus, subway), taxi, private car (i.e., driver), and other (i.e., mainly car passenger, motorcycle). Due to topographic conditions (e.g., pronounced differences in elevation), sociocultural attitudes (e.g., women rarely cycle) and the absence of suitable infrastructure, cycling rates are low. In other words, cycling does not constitute a travel alternative in Tehran, making it unlike European cities in that sense (e.g., Fishman, Böcker, \& Helbich, 2015). Therefore, the subsequent analyses concern three transport modes: private car (driver), public transport and walking. However, the taxi in Tehran is not similar to western societies and the fares are generally low thanks to cheap fuel. We omitted taxis from our models because different types of taxi exist in Tehran. Some are private taxis (dar baste, closed door, or conventional) while others are shared taxis (savaris or na dar baste, collective taxis, shuttle) or telephone taxis (agency taxis or Ajans). However, the prices are different and we therefore excluded taxis from further analyses. Three purposes were distinguished, namely trips for work, leisure or shopping. Based on a literature review (e.g., Feng et al. 2013b; Giuliano \& Narayan, 2003) our independent variables were divided into eight personalhousehold attributes and characteristics of the residential environment related to two traffic zones. Table 2 gives an overview of the variables and provides some descriptive statistics. 
Table 2: Basic statistics of the sample

\begin{tabular}{|c|c|c|c|c|}
\hline Variables & $\begin{array}{c}\text { Sheikhadi } \\
\text { (Located in RTZ) }\end{array}$ & $\begin{array}{c}\text { Qezelqale } \\
\text { (Located in OEZ) }\end{array}$ & $\begin{array}{c}\text { Qeitarie } \\
\text { (out of two zones) }\end{array}$ & Total Samples \\
\hline Gender (Female) (\%) & 46.6 & 51.9 & 56.3 & 51.9 \\
\hline Age (Mean) & 31.68 & 37.4 & 36.15 & 35.07 \\
\hline Car ownership* (\%) & 39.9 & 62.3 & 68.2 & 70.5 \\
\hline \multicolumn{5}{|l|}{ Type of family (\%) } \\
\hline Non-worker single & 12.3 & 14.1 & 18.3 & 14.9 \\
\hline Worker single & 17.4 & 19.9 & 26.9 & 21.4 \\
\hline One-worker family & 42.1 & 39.9 & 34.4 & 38.8 \\
\hline More than one-worker family & 28.2 & 26.1 & 20.4 & 24.9 \\
\hline Presence of child under $12(\%)$ & 24.7 & 20.4 & 17.6 & 20.9 \\
\hline \multicolumn{5}{|l|}{ Income Level (\%) } \\
\hline High* (more than 776 USD per month) & 29 & 34.8 & 37.6 & 33.8 \\
\hline $\begin{array}{l}\text { Middle (between } 776 \text { to } 388 \text { USD per } \\
\text { month) }\end{array}$ & 45.1 & 41.3 & 39.6 & 42.0 \\
\hline Low (less than 388 USD per month) & 25.9 & 23.9 & 22.8 & 25.1 \\
\hline \multicolumn{5}{|l|}{ Education level (\%) } \\
\hline High (master degree and higher) & 20.4 & 28.4 & 34.9 & 27.9 \\
\hline $\begin{array}{l}\text { Intermediate (associate and bachelor } \\
\text { degrees) }\end{array}$ & 44.3 & 38.7 & 34.7 & 39.2 \\
\hline Low (high-school diploma and lower) & 35.3 & 32.9 & 30.4 & 32.9 \\
\hline \multicolumn{5}{|l|}{ Type of job (\%) } \\
\hline $\begin{array}{l}\text { Non-worker: less than } 10 \text { hours per } \\
\text { week }\end{array}$ & 14.9 & 15.4 & 15.7 & 15.3 \\
\hline $\begin{array}{l}\text { Part-time worker: between 10-30 hours } \\
\text { per week }\end{array}$ & 21.9 & 22.3 & 22.7 & 22.3 \\
\hline $\begin{array}{l}\text { Full-time worker: more than } 30 \text { hours } \\
\text { per week }\end{array}$ & 61.9 & 62.3 & 62.9 & 62.5 \\
\hline \multicolumn{5}{|l|}{ Trip purpose (\%) } \\
\hline Work & 44.7 & 38.5 & 48.7 & 43.9 \\
\hline Leisure & 16 & 35.4 & 20.4 & 23.9 \\
\hline Shopping & 15.4 & 19.2 & 22.2 & 18.9 \\
\hline \multicolumn{5}{|l|}{ Modal split (\%) } \\
\hline Walking & 19.9 & 19.7 & 19 & 19.5 \\
\hline Public transport & 43.0 & 18.7 & 25.6 & 29.2 \\
\hline Car & 16.2 & 27.5 & 30.4 & 24.7 \\
\hline Taxi & 13.5 & 30.6 & 22.6 & 22.2 \\
\hline Other modes*** & 7.4 & 3.5 & 2.4 & 4.4 \\
\hline
\end{tabular}

* Percentage of household having car. ${ }^{* *}$ Income was reported in IR Rial and converted to USD (1 USD = 25,776 IR Rial).

*** Others include ferry and motorcycle. Note that the share of motorcycles was higher in "RTZ" than in the other zones.

\section{$5 \quad$ Analytical methods}

First, we developed multinomial logit models for work, leisure and shopping trips to explain transport mode choices made among alternatives (Ben-Akiva \& Lerman, 1985). In each model, walking and public transport are considered relative to automobile use, 'car' thus serving as reference category. Individual and household characteristics are expected to influence mode choices. Second, to investigate the determinants of travel time, a standard ordinary least squares regression was not considered suitable 
because such a model wrongly assumes that travel times are not censored to zero and could also wrongly estimate negative travel times. Therefore, we estimated Tobit regression models (McDonald \& Moffitt, 1980; Greene, 2011; Fishman et al., 2015), which circumvent these shortcomings by dealing with censored data and data comprising only positive values.

\section{$6 \quad$ Results}

The results are presented in two parts, comprising mode choice and travel time analyses. Each part is built of three regression models for three trip purposes.

\subsection{Mode choice}

The estimated results of the multinomial logit models for walking on leisure and shopping trips are given in Tables 3-5. With Nagelkerke $\mathrm{R}^{2}$ s between 0.698 and 0.459 , the fits are good. Most of the socioeconomic and demographic characteristics for work trips display a significant relationship with car use. The first significant variable in the work-trips model (Table 3 ) is gender. The exponentiated coefficient for gender is 2.084 , meaning that females are more likely than males to walk. This result is in line with the findings of Pan, Shen, and Zhang (2009) for Shanghai. One reason could be that working women choose to live closer to their workplace. In Iran, a household selects the residential location in a way that commuting time for male is reduced. However, if women have a full-time job as well, households prefer to choose a residential location close to the women's workplace. A key reason might be that employed women in Iran spent more hours on family responsibilities than employed men (Mortazavi, Pedhiwalab, Shafiroc, \& Hammer, 2009). Like in other Muslim societies, Iranian households think that increased female commuting interferes with women's household duties (The World Bank, 2013). Generally, in Iranian society women do not want to walk just for necessary activities. Also, the likelihood of choosing the car for work trips is 0.674 times higher than choosing walking when people have a car in their households. The model shows that elderly commuters are most likely to walk for work trips. Similar to findings from previous research (e.g., O’Fallon, Sullivan, \& Hensher, 2004), a commuter with children in the household will take the car more often than a commuter from a household without children. The socioeconomic variables (i.e., having car in household, educational level, income level, type of job), and demographic variables (i.e., type of family, presence of child) do not have a significant influence on walking with respect to car use. This is probably why walking cannot compete with the car or other modes in Tehran, especially for work trips. Long home-work distances are predominating which compels people to use the car and other modes instead of walking. However, women tend to live closer to their workplace than men.

Interestingly, women have a slightly lower tendency than men to use public transport for work trips, which is inconsistent with existing European studies (e.g., Schwanen, Dieleman, \& Dijst 2001). One reason is that in Iranian public transport, separate spaces have been designated for women and these spaces are much smaller than those for men. The shortage of women's space would be worst at peak times. Just two coaches of each train and less than half of all bus seats (especially in Bus Rapid Transit) are allocated to women. The likelihood of choosing public transport for work trips is 0.573 times lower than choosing the car, when people have a car in their household. This is in line with findings of Schwanen et al. (2001) for the Netherlands. The probability of using public transport increases with decreasing income and education levels. The model shows that elderly travelers are most likely to take public transport to work. Additionally, employment status which refers to full and part time jobs has an impact on mode choice. People with a full-time job are more inclined to use the car than those with a part-time job. An explanation might read as follows. Both income level and access to a car among people working part 
time are lower than among people with a full-time job. Only one category of the family-type variable is significant in the work-trip model: that is found where the ratio of using public transport for a family with one worker has a positive sign and is larger than the ratio of using a car.

As mentioned in previous sections, one of the main aims of this research is to show how and to what extend traffic zones influence on mode choice. For that purpose, living in one of these zones is considered as an independent variable that would affect travel mode choice. To demonstrate this effect, the variable of neighborhood, which reflects the traffic policies, is included in our regression models. It is statistically significant in all three models. The chi-square for residential environment in the work-trips model shows the highest correlation with mode choice. Living in the RTZ is taken as a reference category. As shown in Table 3, two categories of this variable display a negative relationship with walking. The parameter B for living outside the two traffic zones has a value of -2.037 , meaning that the odds of choosing to walk are -2.037 times less than the odds of choosing a car for work trips. Similar results have been obtained for the OEZ. The odds of choosing to walk decrease for people who live in the OEZ; they walk -0.771 times less than those who choose the car. From the magnitudes of the odds ratio, we can rank the three neighborhoods in terms of their residents' walking preference. In the walking model, having a home outside the two traffic zones has the largest odds ratio for taking the car over walking. In the OEZ, the odds ratio is smaller. The neighborhood with the smallest odds ratio is the RTZ (taken as reference neighborhood).

Similarly, use of public transport is significantly lower than car use. People living outside the two traffic zones make extensive use of a car rather than taking public transport for work trips. Despite traffic policy in the OEZ, living in this zone is associated with a markedly lower use of public transport. It is interesting that the use of public transport relative to the car in the OEZ tends to be lower than in areas outside the two traffic zones. This could be attributed to the lack of a metro station in Qezelqale, which is in the OEZ. Furthermore, police check only the entrances to the OEZ, so residents who work outside this zone might violate the rule and drive to work even on days they are not allowed to do so. Statistics show that the rate of violations at some entrances is over 60 percent (Alenoori, Mirbaha, \& Adibfar 2013). That is probably one of the reasons why cameras were installed in April 2015 to monitor the OEZ. Others could be the use of taxis, the postponement of trips or carpooling. The odd ratios for public transport versus car use suggest that using public transport is preferred least by residents of the OEZ, followed by those living outside the two zones, and then by those in the RTZ. 
Table 3: Results of the multinomial logistic regression model for work trips

\begin{tabular}{|l|c|c|c|c|c|}
\hline \multirow{2}{*}{ Variables } & \multicolumn{2}{|c|}{ Walking } & \multicolumn{2}{c|}{ Public transport } & \multirow{2}{*}{ Chi-square } \\
\cline { 2 - 5 } & $\mathbf{B}$ & $\mathbf{E x p}(\mathbf{B})$ & $\mathbf{B}$ & $\mathbf{E x p}(\mathbf{B})$ & \\
\hline Gender (ref = male) & $0.735^{* *}$ & 2.084 & $-0.335^{* *}$ & 0.715 & $38.951^{* * *}$ \\
\hline Having car (ref = no) & $-0.394^{*}$ & 0.674 & $-0.557^{* * *}$ & 0.573 & $15.864^{* * *}$ \\
\hline Income: low level (ref = high) & $-0.185^{*}$ & 0.831 & -0.368 & 0.692 & $43.656^{* *}$ \\
\hline \multicolumn{1}{|c|}{ middle level } & $-0.227^{*}$ & 0.797 & $-0.490^{* *}$ & 0.613 & \\
\hline Education: high level & -0.433 & 0.649 & $-0.818^{*}$ & 0.277 & $26.216^{* *}$ \\
\hline Education: intermediate level (ref= low) & 0.124 & 1.132 & $-0.198^{* * *}$ & 0.509 & \\
\hline Age & $0.109^{* * *}$ & 1.115 & $0.050^{* * *}$ & 1.051 & $309.839^{* * *}$ \\
\hline Full-time: more than 30 hours per week & 0.127 & 1.135 & $-0.882^{* * *}$ & 0.414 & $24.336^{* *}$ \\
\hline Part-time: between 10 and 30 hours per week(ref= non-workers) & 0.476 & 1.609 & 0.373 & 1.452 & \\
\hline Family with more than one worker & -0.930 & 2.535 & -0.281 & 0.755 & $27.615^{* *}$ \\
\hline Family with one worker & 0.719 & 2.053 & $0.464^{* * *}$ & 1.591 & \\
\hline Single worker (ref= single non-worker) & 1.194 & 3.311 & -0.073 & 0.930 & \\
\hline Presence of child (ref= no) & $-0.065^{*}$ & 0.937 & $-0.843^{* * *}$ & 0.430 & $74.917^{* * *}$ \\
\hline Home outside the two traffic zones & $-2.037^{* * *}$ & 0.130 & $-1.642^{* * *}$ & 0.194 & $223.116^{* * *}$ \\
\hline Home in OEZ (ref= Home in RTZ) & $-0.771^{* *}$ & 0.463 & $-2.590^{* * *}$ & 0.075 & \\
\hline Nagelkerke R ${ }^{2}$ & 0.459 & & & & \\
\hline-2 Log Likelihood null model & 3221.145 & & & & \\
\hline-2 Log Likelihood final model & 2444.627 & & & & \\
\hline$\chi^{2}$ & 776.519 & & & & \\
\hline Reference category= car use & & & & & \\
\hline
\end{tabular}

Signif. codes: ${ }^{*} \alpha \leq 0.10,{ }^{* *} \alpha \leq 0.05,{ }^{* * *} \alpha \leq 0.01$

Regressing for leisure trips indicates that the likelihood that women will choose to walk is lower than choosing the private car. This result is in line with Moeini's (2012) findings for Tehran. It reflects the unfavorable attitudes towards women's presence in public spaces in Iran, dress codes, men's dominant role in the family, and a sense of potential threat, all of which make women feel uncomfortable about walking. Similar to the results for work trips, falling into the categories of a high level of income and education, having a child and having a car in the household prove to decrease the likelihood of walking. Use of public transport rather than the car is low among women for leisure trips, as it is for the trip to work. Again, the elderly are more likely to use public transport than the car on leisure trips.

Regarding the residential environment, the regression for leisure trips shows a higher chi-square for this variable than the regression for work trips showed. Thus, the influence of this variable on mode choice becomes stronger for leisure trips. Similar to the results for work trips, living out of two zones is still negatively related to walking. The exponentiated coefficient value is -2.302 for living outside the two zones, which means that the odds of choosing to walk are 2.3 times lower than the odds of choosing the car. Similarly, living in the OEZ has a significant relationship with walking. The value of the exponentiated coefficient indicates that the likelihood of walking will decrease 1.2 times for people living in the OEZ. The same applies to public transport versus driving. People use the car more frequently than public transport when they live outside the two traffic zones. Again, the negative sign for the OEZ suggests a preference for car use over public transport. In view of the odds ratios, we conclude that car use is chosen most by residents outside the two traffic zones, next by those in the OEZ, followed by those in the RTZ. Therefore, car use for leisure trips in the OEZ is higher than in the RTZ but lower than in neighborhoods outside the two traffic zones. 
Table 4: Results of the multinomial logistic regression model for leisure trips

\begin{tabular}{|l|c|c|c|c|c|}
\hline \multirow{2}{*}{ Variables } & \multicolumn{2}{|c|}{ Walking } & \multicolumn{2}{c|}{ Public transport } & \multirow{2}{*}{ Chi-square } \\
\cline { 2 - 5 } & $\mathbf{B}$ & $\mathbf{E x p}(\mathbf{B})$ & $\mathbf{B}$ & $\mathbf{E x p}(\mathbf{B})$ & \\
\hline Gender (ref=male) & $-1.685^{* * *}$ & 0.186 & $-0.269^{*}$ & 0.649 & $77.094^{* * *}$ \\
\hline Having car (ref=no) & $-0.750^{* *}$ & 0.472 & $-0.787^{* *}$ & 0.455 & $16.285^{* * *}$ \\
\hline Income: low level & -0.475 & 0.622 & -0.245 & 0.783 & 8.184 \\
\hline Income: middle level (ref= high) & $-0.799^{* *}$ & 0.450 & $-0.683^{*}$ & 0.505 & \\
\hline Education: high level & $-0.251^{*}$ & 0.778 & $-0.708^{* *}$ & 0.677 & 6.807 \\
\hline Education: intermediate level (ref=low) & $0.166^{*}$ & 1.180 & -0.389 & 0.493 & \\
\hline Age & $-0.029^{*}$ & 0.971 & $0.140^{* * *}$ & 1.151 & $123.587^{* * *}$ \\
\hline Full-time: more than 30 hours per week & -0.228 & 0.796 & -0.303 & 0.738 & \\
\hline Part-time: between 10 and 30 hours per week (ref= non-workers) & -0.126 & 0.881 & -0.196 & 0.822 & \\
\hline Family with more than one worker & -1.866 & 0.163 & -1.786 & 0.168 & \\
\hline Family with one worker & $-1.197^{* *}$ & 0.302 & $-1.006^{* * *}$ & 0.366 & $38.134^{* *}$ \\
\hline Single worker (ref= single non-worker) & -1.813 & 0.155 & -1.621 & 0.198 & \\
\hline Presence of child (ref=no) & $-0.882^{* *}$ & 0.414 & $-1.639^{* * *}$ & 0.194 & $74.917^{* * *}$ \\
\hline Home outside the two traffic zones & $-2.302^{* * *}$ & 0.100 & $-3.340^{* * *}$ & 0.035 & $267.650^{* * *}$ \\
\hline Home in OEZ (ref= Home in RTZ) & $-1.250^{* * *}$ & 0.286 & $-0.533^{* *}$ & 0.587 & \\
\hline Nagelkerke R ${ }^{2}$ & 0.698 & & & & \\
\hline-2 Log Likelihood null model & $1,887.793$ & & & & \\
\hline-2 Log Likelihood final model & $1,065.914$ & & & & \\
\hline$\chi^{2}$ & 821.879 & & & & \\
\hline Reference category: car use & & & & \\
\hline
\end{tabular}

Signif. codes: ${ }^{*} \alpha \leq 0.10,{ }^{* *} \alpha \leq 0.05,{ }^{* * *} \alpha \leq 0.01$

For shopping trips, women choose walking and public transport more frequently than men unlike leisure trips. When investigating the amount of time they spent traveling, we realized that women did most of their shopping close to home. Moreover, walking and using public transport were relatively higher among the elderly but lower among people with a car and a child in the household. In that respect, the shopping regression resembles that for work trips. When we included the residential environment, the results differed from those of the other two models. Given its chi-square, this variable has great weight in the shopping model. However, it is somewhat smaller than the chi-square for work and leisure trips. The coefficient for this variable is positive. This evidences that living out of the two zones is associated with highly likelihood of walking for shopping trips. Similarly, the value of the exponentiated coefficient for living in the OEZ implies that the odds that people in this zone will walk are 1.7 times higher than the odds that they will take the car. The same applies to the use of public transport relative to the car. Given the odds of 3.496 for living outside the two zones, the residential environment has a substantial effect on the likelihood of using public transport rather than the car. Again, the results for living in the OEZ show a positive significant effect on using public transport. The same neighborhood ranking is observed for public transport over car use. The difference between this model and the models for work and leisure trips is related to three facts. The underlying reason may be the frequency of shopping trips. Descriptive analysis illustrates that the frequency of shopping trips in neighborhoods located outside the two zones and comparatively in the OEZ is much higher than for neighborhoods in the RTZ. Furthermore, most of the shopping trips were undertaken close to home. The proximity of shops induces people to walk and take public transport for shopping purposes.

Besides, people living outside the two zones and in the OEZ may shop online or place phone orders more often than residents in the RTZ. Such behavior is consistent with their higher levels of 
education and income and is associated with a higher incidence of e-shopping (Perea y Monsuwe, Dellaert, \& de Ruyter, 2004). However, there is no reliable evidence of online shopping among people in these two neighborhoods. Moreover, according to the Tehran Master Plan (2006), there are insufficient urban facilities and services at the neighborhood level (e.g., fruit and vegetable markets), especially in the city center (Atlas Tehran, 2010). The higher price of land in Central Tehran might affect access to grocery stores. The likelihood of using the car for shopping trips in the RTZ tends to be high due to the inadequate availability of grocery stores close to the residents' home. Our model does not show that other variables have a significant impact on mode choice. The weight of the chi-square for residential environment explains the relative share and importance of this variable in mode choice. The weight of the chi-square for residential environment is highest for leisure trips; it is smaller for work trips and lowest for shopping trips.

Table 5: Results of the multinomial logistic regression model for shopping trips

\begin{tabular}{|c|c|c|c|c|c|}
\hline \multirow{2}{*}{ Variables } & \multicolumn{2}{|c|}{ Walking } & \multicolumn{2}{|c|}{ Public transport } & \multirow{2}{*}{ Chi-square } \\
\hline & B & $\operatorname{Exp}(B)$ & B & $\operatorname{Exp}(B)$ & \\
\hline Gender (ref=male) & $1.194^{* * *}$ & 3.302 & $0.110^{* * *}$ & 1.116 & $138.461^{* * *}$ \\
\hline Having car (ref=no) & $-0.617^{*}$ & 0.540 & $-1.547^{* * *}$ & 0.213 & $13.014^{* *}$ \\
\hline Income: low level & $-0.092^{*}$ & 0.912 & -0.021 & 0.979 & 0.407 \\
\hline Income: middle level(ref=high) & -0.138 & 0.871 & 0.007 & 1.007 & \\
\hline Education: high level & $-0.528^{*}$ & 0.59 & $-0.495^{*}$ & 0.610 & 3.140 \\
\hline Education: intermediate level (ref=low) & $0.282^{*}$ & 1.326 & $0.388^{*}$ & 1.474 & \\
\hline Age & $0.200^{* * *}$ & 1.221 & $0.173^{* * *}$ & 1.188 & $49.706^{* * *}$ \\
\hline Full-time: more than 30 hours per week & -0.326 & 0.721 & $0.057^{*}$ & 1.058 & 2.749 \\
\hline Part-time: between 10 and 30 hours per week (ref=non-workers) & 0.598 & 1.818 & 1.002 & 2.723 & \\
\hline Family with more than one worker & 0.488 & 1.629 & 0.512 & 1.668 & 4.921 \\
\hline Family with one worker & 1.728 & 4.644 & 1.598 & 4.591 & \\
\hline Single worker(ref= single non-worker) & 0.436 & 1.546 & 0.398 & 1.489 & \\
\hline Presence of child (ref=no) & $-0.498^{*}$ & 0.608 & $-.196^{* *}$ & 0.822 & $56.717^{* * *}$ \\
\hline Home outside the two traffic zones & $1.308^{* *}$ & 3.700 & $1.252^{* *}$ & 3.496 & $113.624^{* * *}$ \\
\hline Home in OEZ (ref=Home in RTZ) & $0.576^{* *}$ & 1.779 & $1.050^{* *}$ & 2.859 & \\
\hline Nagelkerke R2 & 0.621 & & & & \\
\hline -2 Log Likelihood null model & 785.776 & & & & \\
\hline -2 Log Likelihood final model & 398.395 & & & & \\
\hline$\chi^{2}$ & 387.381 & & & & \\
\hline Reference category: car use & & & & & \\
\hline
\end{tabular}

Signif. codes: ${ }^{*} \alpha \leq 0.10,{ }^{* *} \alpha \leq 0.05,{ }^{* * *} \alpha \leq 0.01$

\subsection{Travel time}

Applying Tobit regression models, we estimated how variables affect the amount of time spent traveling in three sets of models, namely those for work, leisure and shopping trips, as presented in Table 6. For work trips, women spent less time traveling than men. Similar findings have been reported for Seoul, South Korea by Lee and McDonald (2003). For leisure and shopping trips, women tend to have longer travel times than men. Having a car in the household increases travel time for work and leisure trips but decreases travel time for shopping trips. In contrast to other studies (e.g., Wang \& Chai, 2009; Feng et al., 2013a), our models show that people who belong to the lowest income category spend more time on traveling than people in the high-income segment. One reason could be that people with lower income travel longer distances between workplace and their residential location. A second explanation might be that they use public transport which requires the longest travel time among the considered modes. 
Similar results were found for education. Consistent with findings of Schwanen, Dijst, and Dieleman (2002), we found that older people have short commuting times. However, due to the use of slow modes in combination with the rather dispersed distribution of recreational and shopping places, they have long travel times for leisure and shopping trips. In line with the literature (e.g., Schwanen \& Dijst, 2002; Feng et al., 2013b), we found that as work duration increases, so does travel time for work trips. The work duration is not significant for the leisure and shopping models. In line with other studies (e.g., Lee \& McDonald, 2003), having a child reduces the amount of time spent traveling. The negative signs for families in the work and shopping models indicate that they spend less time commuting than single non-workers as the reference category. For leisure trips, the coefficient for all families is positive, indicating that they spend more time on travel than single non-workers. In line with the literature, families with more than one worker tend to shorten their travel time for leisure and shopping purposes.

The traffic policy of one's residential location has a high correlation with travel time. Generally, people residing outside the two traffic zones spend less time traveling for work or shopping compared to those living in the RTZ. This also applies to people living in the OEZ. An explanation may be that although public transport is prevalent in the RTZ, it takes longer than the travel modes. In our three samples, the average amount of travel time in minutes by mode choice and residential location indicates that people spend about one hour in public transport while the average travel time by car is half an hour.

The results of the leisure-trips model differ from those of the other two. The coefficient for residential location is positive. Similar to the two other models, living in the OEZ is associated with longer travel times than living outside the two traffic zones. One reason might be the proximity of the unrestricted neighborhood to many leisure destinations in the north of Tehran. Known for its hilly terrain and good weather, the north of Tehran is a destination for many recreational trips. People living in unrestricted areas have many entertainment destinations in the immediate vicinity, they cover shorter distances for recreation, and they spend less time traveling. Generally, the residential variable is more significant when traveling for leisure than for other purposes.

Table 6: Results of the Tobit regression models for time spent traveling

\begin{tabular}{|c|c|c|c|c|c|c|}
\hline \multirow{2}{*}{ Variables } & \multicolumn{2}{|c|}{ Work trip } & \multicolumn{2}{|c|}{ Leisure trip } & \multicolumn{2}{|c|}{ Shopping trip } \\
\hline & B & ZValue & B & ZValue & B & ZValue \\
\hline Gender (ref=male) & $-0.0357^{* * *}$ & -14.458 & $0.808^{* * *}$ & 17.395 & $0.111^{*}$ & 0.710 \\
\hline Having car $(\mathrm{ref}=\mathrm{no})$ & $0.061^{* *}$ & 2.322 & $0.065^{* *}$ & 1.601 & $-0.046^{*}$ & -0.520 \\
\hline Income: middle level & -0.033 & -1.148 & $0.032^{*}$ & 1.032 & 0.029 & 0.294 \\
\hline Income: high level (ref=low) & $-0.048^{*}$ & -1.177 & $-0.038^{*}$ & 0.962 & $-0.001^{*}$ & -0.004 \\
\hline Education: intermediate level & $0.011^{*}$ & 0.304 & 0.041 & 0.829 & $-0.131^{*}$ & -1.093 \\
\hline Education: low level(ref=high) & $0.030^{*}$ & 0.850 & $0.072^{* *}$ & 1.378 & 0.055 & 0.486 \\
\hline Age & $-0.006^{* * *}$ & -5.363 & $0.054^{* * *}$ & 28.075 & $0.011^{* *}$ & 1.483 \\
\hline Family with more than one worker & $-0.156^{* *}$ & -1.645 & $0.434^{* *}$ & 2.493 & $-0.443^{*}$ & -1.351 \\
\hline Family with one worker & $-0.130^{* *}$ & -1.395 & $0.449^{* *}$ & 2.648 & $-0.403^{*}$ & -1.248 \\
\hline Single worker(ref=single non-worker) & $-0.163^{* *}$ & -1.809 & $0.533^{* *}$ & 3.045 & $-0.351^{*}$ & -1.118 \\
\hline Full-time: more than 30 hours per week & $0.032^{*}$ & 0.693 & 0.045 & 0.862 & 0.051 & 0.369 \\
\hline Part-time: between 10 and 30 hours per week (ref=non-worker) & $0.017^{*}$ & 0.436 & -0.050 & -0.664 & -0.094 & 0.597 \\
\hline Presence of child ( ref=no) & $0.183^{* * *}$ & 5.086 & $0.981^{* * *}$ & 18.554 & $0.995^{* * *}$ & 4.333 \\
\hline Home outside the traffic zones & $-0.140^{* * *}$ & -4.505 & $0.351^{* * *}$ & 7.220 & $-0.231^{* *}$ & -2.525 \\
\hline Home in OEZ (ref=Home in RTZ) & $-0.048^{*}$ & -1.563 & $0.549^{* * *}$ & 9.067 & $-0.270^{* *}$ & -1.525 \\
\hline (Intercept) & $8.482^{* * *}$ & & $4.527^{* * *}$ & & $7.621^{* * *}$ & \\
\hline Log likelihood model & \multicolumn{2}{|c|}{-11386.137} & \multicolumn{2}{|c|}{-6719.021} & \multicolumn{2}{|c|}{-3611.616} \\
\hline LR chi ${ }^{2}$ & \multicolumn{2}{|c|}{187.98} & \multicolumn{2}{|c|}{454.47} & \multicolumn{2}{|c|}{37.88} \\
\hline Prob $>$ chi $^{2}$ & \multicolumn{2}{|c|}{0.000} & \multicolumn{2}{|c|}{0.000} & \multicolumn{2}{|c|}{0.000} \\
\hline Pseudo $\mathrm{R}^{2}$ & \multicolumn{2}{|c|}{0.082} & \multicolumn{2}{|c|}{0.32} & \multicolumn{2}{|c|}{0.052} \\
\hline $\mathrm{N}$ & \multicolumn{2}{|c|}{1375} & \multicolumn{2}{|c|}{756} & \multicolumn{2}{|c|}{545} \\
\hline
\end{tabular}

Signif. codes: ${ }^{*} \alpha \leq 0.10,{ }^{* *} \alpha \leq 0.05,{ }^{* * *} \alpha \leq 0.01$ 


\section{$7 \quad$ Discussion and conclusions}

The main objective of this paper was to evaluate the effects of two types of car restriction measures on travel mode choice and travel time in Tehran, a city confronted with heavy transport-related pollution. These traffic policies partition Tehran into three zones. In the Restricted Traffic Zone (RTZ) car driving is banned in certain time windows, while in the Odd-Even Zone (OEZ) cars are restricted on the basis of odd- and even-numbered license plates in certain time windows. The rest of the city has no restrictions. Multivariate regressions are used to analyze the impact of both traffic zones on mode choice and travel time, differentiated by trip purpose.

The results show that for work and leisure trips the usage of cars in the RTZ is much lower than public transport and walking. Because the predominant modes are relatively slow, the average travel time for all trip purposes in this zone is slightly higher than in the OEZ and much higher than outside the two traffic zones. In the OEZ, people are more likely to use the car than to walk or take public transport. Car usage in the OEZ is much higher than in the RTZ but less than elsewhere. Also travel time in the neighborhood located in the OEZ is slightly lower than in the RTZ but higher than in the neighborhood located outside the two zones. Despite restrictions on driving in the OEZ, people use public transport for work trips less than those living in the unrestricted neighborhood. This gives the impression that people living in the OEZ prefer to use the car every other day. They may have postponed certain trips or may carpool with people who are authorized to drive that particular day. Note that violation of the odd-even car regulation is more prevalent than the strategy of buying an additional car, due to the low-income levels in Tehran. Because only the gateways of the OEZ are monitored by police, the spotty control leads to an increase in traffic violations (Tarahan Parseh Transportation Research Institute, 2011). In the RTZ, by contrast, cameras are used to monitor entering vehicles. The use of other transport modes such as taxis and the lack of a metro station in the selected OEZ neighborhood could be other reasons for people not to take public transport for work trips. In the neighborhood where driving is not restricted, the car is the prevalent mode. Car usage in these areas is much higher than in the RTZ but slightly higher than in the OEZ. Travel time in these areas is less than in the two traffic zones. Surprisingly, for shopping trips, car usage in the RTZ is much higher than in the OEZ and outside the two traffic zones. This might be because shopping trips in the RTZ are much more frequent than in the two other neighborhoods and are undertaken close to the residents' home. There might be other reasons as well. One could be online shopping or placing a phone order among people living outside the two zones and in the OEZ; another could be the inadequate presence of grocery stores close to residents' homes in the RTZ, to name a few.

In general, Tehran is a unique case in the field of travel demand management, in the sense that two different types of TDM measures could be compared in the same environment. We conclude that both measures cause residents to decrease their car usage and thereby lead to an increase in travel time. It also becomes clear that the OEZ scheme is more flexible than the RTZ scheme in allowing residents to postpone car trips or to use another person's car. Concerning driving, our key findings are in line with the literature. The lower car usage found for Tehran has been also found for Beijing's OEZ (e.g., Liguang et al., 2010) and London's RTZ (Litman, 2011). Our findings for travel time differ from those in previous studies. In contrast to Stockholm (e.g., Albalate \& Bel, 2008) and London (Litman, 2011), we found that both types of car restrictions caused an increase in travel time. A possible reason could be the insufficient infrastructure for alternative modes such as public transport, walking and cycling. Moreover, the functional specialization in the urban space and being a monocentric city with a major $\mathrm{CBD}$, where most commercial activities are concentrated, combine to induce more car trips and longer travel time.

Despite this study was the first analyzing the impact of traffic zones on people's mobility in Tehran, the following limitations must be mentioned. First, the sample does not entirely mirror the population 
at the neighborhood level. Second, although following existing studies (e.g., Christiansen, Engebretsen, Fearnley, \& Usterud, 2017), we assumed that the application of the multinomial logit model to analyze people's travel mode choice is in line with the independence of irrelevant alternatives assumption.

It is important for Tehran's policymakers to realize that while the RTZ reduces car use, it increases travel time. To avoid the negative impact on travel time it might be worth considering the example of Singapore, where vehicle restriction is integrated with other policy measures such as high-quality walking, cycling and public transit (Strompen et al., 2012). Due to geographical limitations (e.g., large difference in elevation) and particular social-cultural characteristics (e.g., being unaccustomed to cycling, especially among women) measures to stimulate cycling and walking might not be as successful for Tehran as they have been in many European and developing countries. As Tehran is on the way from a monocentric, car-oriented city to a polycentric, transit-oriented city (Tehran Master Plan 2006), it can be expected that high quality railroad systems in combination with walkable, high-density, and mixed land use (e.g., residential, offices, retail) around the transit nodes will gain importance. 


\section{References}

Amir-Ebrahimi, M. (2006). Conquering enclosed public spaces, Cities, 23(6), 455-461.

Albalate, D., \& Bel, G. (2008). Shaping urban traffic patterns through congestion charging: What factors drive success or failure? Working papers, 1-27. Barcelona, Spain: University of Barcelona, Research Institute of Applied Economics.

Alenoori, H., Mirbaha, B., \& Adibfar, A. (2013, July). Technical and economical comparison of using ITS technology for enforcement of plate number rationing in Tehran (Even-Odd Zone). Paper presented at the 13th World Conference on Traffic Research (WCTR), Rio de Janeiro, Brazil.

Allen, H. (2013). An integrated approach to public transport, Tehran, Iran. (Case study prepared for Global Report on Human Settlements. Retrieved from http:// www.unhabitat.org/grhs/2013.

Arentze, T., Hofman, F., \& Timmermans, H. (2004). Predicting multi-faceted activity-travel adjustment strategies in response to possible congestion pricing scenarios using an Internet-based stated adaptation experiment. Transport Policy, 11(1), 31-41.

Atlas Tehran. (2010). Urban facilities and transportation chapters, in Tehran statistics. Retrieved from http://www.atlas.tehran.ir

Ben-Akiva, M. E. and Lerman, S. R. (1985). Discrete choice analysis: Theory and application to travel demand. Cambridge, MA: MIT Press.

Broaddus, A., Litman, T., \& Menon, G. (2009). Transportation demand management training document. Bonn, Germany: Federal Ministry for Economic Cooperation and Development.

Christiansen, P., Engebretsen, Ø., Fearnley, N., \& Usterud, H. J. (2017). Parking facilities and the built environment: Impacts on travel behavior. Transportation Research Part A, 95, 198-206.

Dargay, J., Gately, D., \& Sommer., M. (2007). Vehicle ownership and income growth, worldwide: 1960-2030. Energy Journal 28(4), 143-170.

Dissanayake, D., \& Morikawa, T. (2002). Household travel behavior in developing countries nested logit model of vehicle ownership, mode choice, and trip chaining. Transportation Research Record, $1805,45-52$.

Feng, J., Dijst, M., Wissink, B., \& Prillwitz, J. (2013a). The impacts of household structure on the travel behavior of seniors and young parents in China. Transport Geography, 30, 117-126.

Feng, J., Dijst, M., Prillwitz, J., \& Wissink, B. (2013b). Travel time and distance in international perspective: A comparison between Nanjing (China) and the Randstad (the Netherlands). Urban Studies, 50(14), 1-18.

Fishman, E., Böcker, L., \& Helbich, M. (2015). Adult active transport in the Netherlands: An analysis of its contribution to physical activity requirements. PLOS One, 10(4): e0121871.

Giuliano, G., \& Narayan, D. (2003). Another look at travel patterns and urban form: The US and Great Britain. Journal of Urban Studies, 40(11), 2295-2312.

Greene, W. H. (2011). Econometric Analysis, seventh edition. London, England: Pearson Education.

Goodwin, P. (2004). Solving congestion. In F. Terry (Ed.), Turning the corner: A reader in contemporary transport policy (pp. 1-19). Hoboken, NJ: Blackwell Publishers.

ICT Organization of Tehran Municipality. (2014). Geographic and demographic statistics of Tehran's neighborhoods. Tehran, Iran: ICT Organization of Tehran Municipality.

International Energy Agency. (2010). World energy outlook, part E, focus on energy subsidies, country subsidy profiles. Retrieved from http//iea.org/media/weo2010.pdf

Leape, J. (2006). The London congestion charge. Economic Perspectives, 20(4), 157-176.

Lee, B. S., \& McDonald, J. F. (2003). Determinants of commuting time and distance for Seoul residents: The impact of family status on the commuting of women. Urban Studies, 40(7), 1283-1302. 
Liguang, F., Haozhi, Z., Yulin, J., \& Zhaorong, W. (2010, March). Evaluation on the effect of car use restriction measures in Beijing. Paper presented at the 51st Annual Transportation Research Forum, Arlington, VA.

Litman, T. (2011). London congestion pricing implications for other cities. Victoria Transport Policy Institute. Retrieved from http://www.vtpi.org/london.pdf

Loukopoulos, P. (2005). Future urban sustainable mobility: Implementing and understanding the impacts of policies designed to reduce private automobile usage (doctoral thesis). Department of Psychology, Gothenburg University, Gothenburg, Sweden.

McDonald, J. F., \& Moffitt, R. A. (1980). The uses of Tobit analysis. Review of Economics and Statistics, 62(2), 318-321.

Mahendra, A. (2008). Vehicle restriction in four Latin American cities: Is congestion pricing possible? Transport Reviews, 28(1), 105-133.

Moeini, S. M. (2012). Attitudes to urban walking in Tehran. Environment and Planning B: Planning and Design, 39(2), 344-359.

Mortazavia, S., Pedhiwalab, N., Shafiroc, M., \& Hammer, L. (2009). Work-family conflict related to culture and gender. Community, Work \& Family, 12(2), 251-273.

O'Fallon, C., Sullivan, C., \& Hensher, D.A. (2004). Constraints affecting mode choices by morning car commuter, Transport Policy, 11(1), 17-29.

Padayhag, G., \& Bahoy, L. (2013). How travel pattern changes after number coding scheme as a travel demand management measure was implemented? Eastern Asia Society for Transportation Studies, 10, 412-426.

Pan, H., Shen, Q., \& Zhang, M. (2009). Influence of urban form on travel behavior in four neighborhoods of Shanghai. Urban Studies, 46(2), 275-294.

Perea y Monsuwe, T., Dellaert, B. G. C., \& de Ruyter, J. C. (2004). What drives consumers to shop online? A literature review. International Journal of Service Industry Management, 15(1), 102-121. doi: 10.1108/09564230410523358

Shams, M., \& Rahimi-Movaghar, V. (2008). Risky driving behaviors in Tehran. Iran Traffic Injury Prevention, 10(1), 91-94.

Schwanen, T., Dijst, M., \& Dieleman, F.M. (2002). A microlevel analysis of residential context and travel time. Environment and Planning A, 34, 1487-1507.

Schwanen, T., Dieleman, F. M., \& Dijst. M. (2001). Travel behavior in Dutch monocentric and policentric urban systems. Transport Geography, 9, 173-186.

Schwanen, T., \& Dijst, M. (2002). Travel-time ratios for visits to the workplace: The relationship between commuting time and work duration. Transportation Research A, 36, 573-592.

Shoar, K. (2008, January). The urban transport challenge — recent innovative policies and measure in Tehran. Paper presented at the International Seminar on Urban Transport in the Mediterranean Region, Skhirat, Morocco.

Strompen, F., Litman, T., \& Bongardt, D. (2012). Reducing carbon emissions through transport demand management strategies: A review of international examples. Final report. Beijing, China: GIZ, Beijing Transport Research Center.

Susilo, Y., Joewono, T., \& Santosa, W. (2010). An exploration of public transport users' attitudes and preferences towards various policies in Indonesia: Some preliminary results. Eastern Asia Society for Transportation Studies, 8, 1230-1244.

Tarahan Parseh Transportation Research Institute. (2011). Effect of mechanization control of area of oddeven zone, volume 4. Tehran, Iran: Tarahan Parseh Transportation Research Institute.

Tehran Comprehensive Transportation and Traffic Studies. (2013). Tehran statistics, chapter 1, Tehran, Iran: Tehran Transportation and Traffic Organization. 
Tehran Master Plan. (2006). Tehran strategic-structural plan (original document), pp 1-54. Tehran, Iran: Deputy of Architecture and Urban Planning.

The World Bank (2014). Economy-and-growth. Retrieved from https://data.worldbank.org/indicator/ NY.GDP.MKTP.KD.ZG?view=chart

The World Bank. (2013). Opening doors gender equality and development in the Middle East and North Africa. Retrieved from http://documents.worldbank.org/curated/en/338381468279877854/pdf/75 1810PUB0EPI002060130Opening0doors.pdf

Van Eck. J. R., Burghouwt, G., Dijst, M. (2005) Lifestyles, spatial configurations and quality of life in daily travel: An explorative simulation study. Journal of Transport Geography 13(2), 123-134.

Viard, V.B., \& Fu., S. (2013). The effect of Beijing's driving restrictions on pollution and economic activity. Public Economics, 125, 98-115.

VTPI. (2004). Online TDM Encyclopedia, Victoria Transport Policy Institute. Retrieved from http// www.vtpi.org

Wang, D., \& Chai, Y. (2009). The jobs-housing relationship and commuting in Beijing, China: The legacy of Danwei. Transport Geography, 17(1), 30-38.

Wang, L., Xu, J., Zheng, X., \& Qin, P. (2013). Will a driving restriction policy reduce car trips? A case study of Beijing, China. Environment for Development Discussion Paper Series. Retrieved from http:// www.rff.org/files/sharepoint/WorkImages/Download/EfD-DP-13-11.pdf

World Health Organization (WHO). (2014). Air pollution. Retrieved from http://www.who.int/phe/ Health_Topics/Outdoorair/Database ambient (outdoor) air pollution by country and city 